\title{
White coat hypertension in early pregnancy in women with pre-existing diabetes: prevalence and pregnancy outcomes
}

\author{
Marianne Vestgaard ${ }^{1,2}$ (D) Björg Ásbjörnsdóttir ${ }^{1,2} \cdot$ Lene Ringholm ${ }^{1,3} \cdot$ Lise Lotte T. Andersen ${ }^{4}$ • Dorte M. Jensen ${ }^{4,5}$. \\ Peter Damm ${ }^{1,2}$. Elisabeth R. Mathiesen ${ }^{1,2}$
}

Received: 12 March 2019 / Accepted: 26 July 2019 / Published online: 18 October 2019

(C) Springer-Verlag GmbH Germany, part of Springer Nature 2019

\begin{abstract}
Aims/hypothesis Hypertensive disorders are prevalent among pregnant women with pre-existing diabetes, but the prevalence and impact of white coat hypertension are unknown. Measurement of home BP before initiation of antihypertensive treatment is necessary to identify white coat hypertension since international guidelines recommend that white coat hypertension is left untreated. The aim of this study, conducted among women with pre-existing diabetes, was therefore to examine the prevalence of white coat hypertension in early pregnancy, and pregnancy outcome in women with white coat hypertension in early pregnancy.

Methods A prospective cohort study was undertaken involving women with pre-existing diabetes from a geographically welldefined area. Based on office BP in early pregnancy and home BP measured for 3 days, women were categorised in three groups: (1) white coat hypertension, defined as office $\mathrm{BP} \geq 135 / 85 \mathrm{mmHg}$ and mean home $\mathrm{BP}<130 / 80 \mathrm{mmHg}$; (2) chronic hypertension, defined as pre-pregnancy hypertension including newly detected office $\mathrm{BP} \geq 135 / 85 \mathrm{mmHg}$ with home $\mathrm{BP} \geq 130$ / $80 \mathrm{mmHg}$; and (3) normotension. Office BP was measured every 2 weeks and, if $\geq 135 / 85 \mathrm{mmHg}$, home BP measurements were performed. White coat hypertension was left untreated, and tight antihypertensive treatment was initiated when both office $\mathrm{BP} \geq 135 / 85 \mathrm{mmHg}$ and home BP $\geq 130 / 80 \mathrm{mmHg}$. Pregnancy-induced hypertensive disorders were defined as office BP $\geq 140$ / $90 \mathrm{mmHg}$ with home $\mathrm{BP} \geq 130 / 80 \mathrm{mmHg}$ when available, with onset after 20 weeks of gestation.

Results In total, 32 out of 222 women with pre-existing diabetes had newly detected office BP $\geq 135 / 85 \mathrm{mmHg}$ in early pregnancy. White coat hypertension was present in $84 \%(27 / 32)$ of these women, representing $12 \%(95 \% \mathrm{CI} 8 \%, 17 \%)$ of the whole cohort. Chronic hypertension was present in $14 \%(n=32)$ and normotension in $74 \%(n=163)$. Women with white coat hypertension were characterised by higher pre-pregnancy BMI $(p=0.011)$, higher home BP $(p<0.001)$ and higher prevalence of type 2 diabetes $(p=0.009)$, but similar $\mathrm{HbA}_{1 \mathrm{c}}(p=0.409)$ compared to women with normotension. Regarding pregnancy outcome, pregnancy-induced hypertensive disorders developed in $44 \%(12 / 27)$ of women with white coat hypertension in comparison with $22 \%(36 / 163)$ among initially normotensive women $(p=0.013)$, while the prevalence of preterm delivery was comparable $(p=0.143)$. The adjusted analysis, performed post hoc, suggested approximately double the risk of developing pregnancy-induced hypertensive disorders (OR 2.43 [CI 0.98, 6.05]) if white coat hypertension was present in early pregnancy, independently of pre-pregnancy BMI and parity.

Conclusions/interpretation White coat hypertension is prevalent in women with pre-existing diabetes and may indicate a high risk of later development of pregnancy-induced hypertensive disorders. To distinguish between persistent white coat hypertension and onset of pregnancy-induced hypertension, repeated home BP monitoring is recommended when elevated office BP is detected.
\end{abstract}

The study was registered at ClinicalTrials.gov (ID: NCT02890836).

Marianne Vestgaard

marianne.jenlev.vestgaard@ regionh.dk

1 Center for Pregnant Women with Diabetes, Department of Endocrinology and Obstetrics, Rigshospitalet, University of Copenhagen, Blegdamsvej 9, 2100 Copenhagen, Denmark

2 Department of Clinical Medicine, University of Copenhagen, Copenhagen, Denmark
3 Steno Diabetes Center Copenhagen, Gentofte, Denmark

4 Department of Obstetrics, Odense University Hospital, Odense, Denmark

5 Steno Diabetes Center Odense, Odense University Hospital, Odense, Denmark 


\section{Research in context}

\section{What is already known about this subject?}

- Guidelines recommend that hypertension presenting in the doctor's office during pregnancy is verified by home BP measurements to exclude white coat hypertension

- Up to $70 \%$ of pregnant women with elevated office BP have white coat hypertension

- The prevalence of white coat hypertension in women with pre-existing diabetes and implications later in pregnancy have not previously been evaluated

\section{What is the key question?}

- Is white coat hypertension prevalent in early pregnancy and does it predict pregnancy outcomes in women with pre-existing diabetes?

\section{What are the new findings?}

- Among women with pre-existing diabetes presenting with elevated office BP in early pregnancy, $84 \%$ had white coat hypertension, corresponding to a prevalence of white coat hypertension of $12 \%$ in the total cohort

- White coat hypertension in early pregnancy was associated with a high prevalence of pregnancy-induced hypertensive disorders later in pregnancy

- Having identified white coat hypertension in women with newly detected elevated office BP in early pregnancy, it is recommended that elevated office BP later in pregnancy is supplemented with home BP measurements

\section{How might this impact on clinical practice in the foreseeable future?}

- Identification of white coat hypertension in early pregnancy enables the antenatal management of these women without using antihypertensive treatment. However, white coat hypertension is not a benign condition, and it is recommended that elevated office BP later in pregnancy is supplemented with home BP measurements to identify any later need for antihypertensive treatment

Keywords Aspirin · Diabetes · Home blood pressure · Hypertension · Preeclampsia · Pregnancy · Pregnancy-induced hypertensive disorders $\cdot$ Pregnancy outcome $\cdot$ White coat hypertension

\section{Abbreviations \\ ACR Albumin/creatinine ratio \\ IQR Interquartile range \\ LGA Large for gestational age \\ NICU Neonatal intensive care unit \\ SGA Small for gestational age \\ SMS Short message service}

\section{Introduction}

Up to $40 \%$ of pregnancies in women with pre-existing diabetes (type 1 or type 2 diabetes) are complicated by hypertensive disorders [1, 2], and the development of preeclampsia shows a sixfold increase in women with diabetes compared with women without diabetes [3]. Verifying the diagnosis of hypertension by either home BP measurements or $24 \mathrm{~h}$ BP measurements is recommended both in non-pregnant and pregnant populations $[4,5]$. This is to exclude white coat hypertension, i.e. elevated BP at the doctor's office, but normal BP in the usual home environment [6], since antihypertensive treatment is not recommended to pregnant women with white coat hypertension $[4,5]$.

In healthy pregnancy up to $70 \%$ of the women who present with hypertension in the office have white coat hypertension $[7,8]$. However, the implications of having white coat hypertension in early pregnancy have only been sparsely investigated in women without diabetes, and results suggest that nearly half of women with initial white coat hypertension in early pregnancy develop hypertension during pregnancy [7]. To our knowledge, the prevalence and implications of white coat hypertension in early pregnancy have never been explored in women with diabetes.

In general, hypertension is defined as office $\mathrm{BP} \geq$ $140 \mathrm{mmHg}$ systolic and/or $90 \mathrm{mmHg}$ diastolic [4]. During pregnancy, antihypertensive treatment is usually only initiated when office BP is well above 140/90 $\mathrm{mmHg}$ due to fear of harming the feto-placental unit $[4,5]$. This approach has recently been challenged by a large randomised clinical trial documenting that tight antihypertensive treatment prevents 
the development of severe hypertension in pregnant women without reported negative consequences for the fetus [9].

An even tighter goal for antihypertensive treatment has been recommended in the non-pregnant population with diabetes [10] because hypertension plays a central role in the development of proteinuria and other microvascular complications $[11,12]$. For more than 10 years we have followed a tight antihypertensive treatment strategy for pregnant women with pre-existing diabetes, when office BP is $\geq 135 \mathrm{mmHg}$ systolic and/or $85 \mathrm{mmHg}$ diastolic [1]. We have demonstrated improved pregnancy outcomes using this office BP target in pregnant women with diabetes and microalbuminuria [13]. This tight antihypertensive goal was also evaluated in a large retrospective cohort of unselected pregnant women with preexisting diabetes, and a reassuringly low prevalence of hypertensive disorders and preterm delivery were reported [1]. Therefore, BP target of $\geq 135 / 85 \mathrm{mmHg}$ was chosen for this study and referred to as 'tight'. Current guidelines $[5,14]$ and cohort studies [15-17] describe home BP as approximately $5 / 5 \mathrm{mmHg}$ lower than office BP, so office BP of 135/ $85 \mathrm{mmHg}$ corresponds to home BP of 130/80 $\mathrm{mmHg}$.

The aim of this study, conducted among women with preexisting diabetes, was therefore to examine the prevalence of women with white coat hypertension in early pregnancy and their pregnancy outcome. White coat hypertension was left untreated and tight antihypertensive treatment initiated when indicated.

\section{Methods}

Study population In this prospective observational cohort study, consecutive pregnant women with pre-existing diabetes were included from September 2015 to February 2018 at two territorial referral centres for pregnant women with diabetes in Copenhagen and Odense, Denmark, covering a geographically well-defined region of approximately four million inhabitants. Inclusion criteria were women with pre-existing diabetes with a singleton pregnancy before 20 weeks of gestation. Exclusion criteria were age $<18$ years, concomitant diseases (cystic fibrosis $[n=2]$, polycystic kidneys $[n=1]$, previous bariatric surgery $[n=4]$ and secondary diabetes due to e.g. pancreatitis $[n=4]$ ), insufficient language skills and recurrent pregnancy during the study period.

Of 393 eligible women, 305 (78\%) women consented to participate. Subsequently, 58 women were excluded as a result of: induced or spontaneous abortion $(n=18)$; withdrawal of consent $(n=39)$; or because they moved to another part of Denmark $(n=1)$, leaving a cohort of 247 women for the study. Home BP measurements were not returned in early pregnancy by $10 \%(n=25)$ of the women, resulting in 222 women (178 from Copenhagen and 44 from Odense) available for analyses.
Monitoring of office BP At the first antenatal visit (median 71 days [interquartile range (IQR) 59-88]), routine office BP was measured once after $5 \mathrm{~min}$ of resting. If values were $\geq 135 \mathrm{mmHg}$ systolic and/or $\geq 85 \mathrm{mmHg}$ diastolic, two further measurements were performed. The lowest obtained office BP was noted in the patient's record and used for analysis. Office BP was measured by Microlife BP 3A Plus, which is validated for use in pregnancy including if preeclampsia develops [18] at Rigshospitalet, and with an A\&D Medical, Life Source UA852 Digital BP Monitor (Abingdon, UK) at Odense University Hospital.

Monitoring of home BP At inclusion, the women received careful oral and written instructions on self-monitoring of home BP with the BP device Microlife BP 3A Plus and on how to fill in the measured BP in a case report form. The women were instructed to initiate the home BP measuring within 1 week of inclusion in the study and to measure home BP for 3 days with three measurements both in the morning before breakfast and in the late afternoon before dinner after a minimum of 5 min rest in a seated position (in total 18 measurements) according to the guidelines from the Danish Hypertension Society [19]. All women were requested to refrain from smoking for at least $30 \mathrm{~min}$ before measuring. Appropriate cuff sizes were used: medium-large if the upper arm circumference was between 22 and $42 \mathrm{~cm}$ and X-large if the upper arm circumference was above $42 \mathrm{~cm}$, which was the case in $5 \%$ of the women. The women were asked to measure home BP in a similar way within 1 week of the visit at 36 weeks. The mean of all recorded home BP measurements was calculated. Current guidelines $[5,14]$ and cohort studies [15-17] describe home BP as approximately $5 / 5 \mathrm{mmHg}$ lower than office BP, so office BP of $135 / 85 \mathrm{mmHg}$ corresponds to home $\mathrm{BP}$ of $130 / 80 \mathrm{mmHg}$.

We sought to improve compliance by sending short message services (SMS). The women received a customised welcome-SMS and reminder-SMSs. Throughout pregnancy the women were asked to measure home BP for 3 days on indication whenever office $\mathrm{BP} \geq 135 \mathrm{mmHg}$ systolic and/or $\geq 85 \mathrm{mmHg}$ diastolic (Fig. 1). The women were asked to bring these measurements to the next clinical appointment, to phone or to mail the measurements using a tailored individual approach.

Antihypertensive treatment Antihypertensive treatment was initiated if office $\mathrm{BP} \geq 135 \mathrm{mmHg}$ systolic and/or $\geq 85 \mathrm{mmHg}$ diastolic together with elevated home BP defined as home $\mathrm{BP} \geq 130 \mathrm{mmHg}$ systolic and/or $\geq 80 \mathrm{mmHg}$ diastolic. Additionally, antihypertensive treatment was initiated if albumin/creatinine ratio (ACR) $>30 \mathrm{mg} / \mathrm{mmol}$, regardless of BP level (Fig. 1). The women were hereafter advised to continue home BP measurements throughout pregnancy and to bring home BP measurements to every pregnancy visit, where 
Fig. 1 Flowchart of the Copenhagen antihypertensive treatment strategy in pregnant women with pre-existing diabetes who have elevated office BP and available data on home BP.

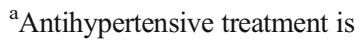
initiated or optimised if office $\mathrm{BP} \geq 135 \mathrm{mmHg}$ systolic and/or $\geq 85 \mathrm{mmHg}$ diastolic together with elevated home BP defined as home $\mathrm{BP} \geq 130 \mathrm{mmHg}$ systolic and/or $\geq 80 \mathrm{mmHg}$ diastolic. Additionally, antihypertensive treatment is initiated if the ACR is $\geq 30 \mathrm{mg} / \mathrm{mmol}$, regardless of BP level. The dual therapeutic goal is to reduce home systolic BP to $<130 \mathrm{mmHg}$ and diastolic BP to $<80 \mathrm{mmHg}$, and to reduce ACR to $<30 \mathrm{mg} / \mathrm{mmol}$. DBP, diastolic blood pressure; SBP, systolic blood pressure

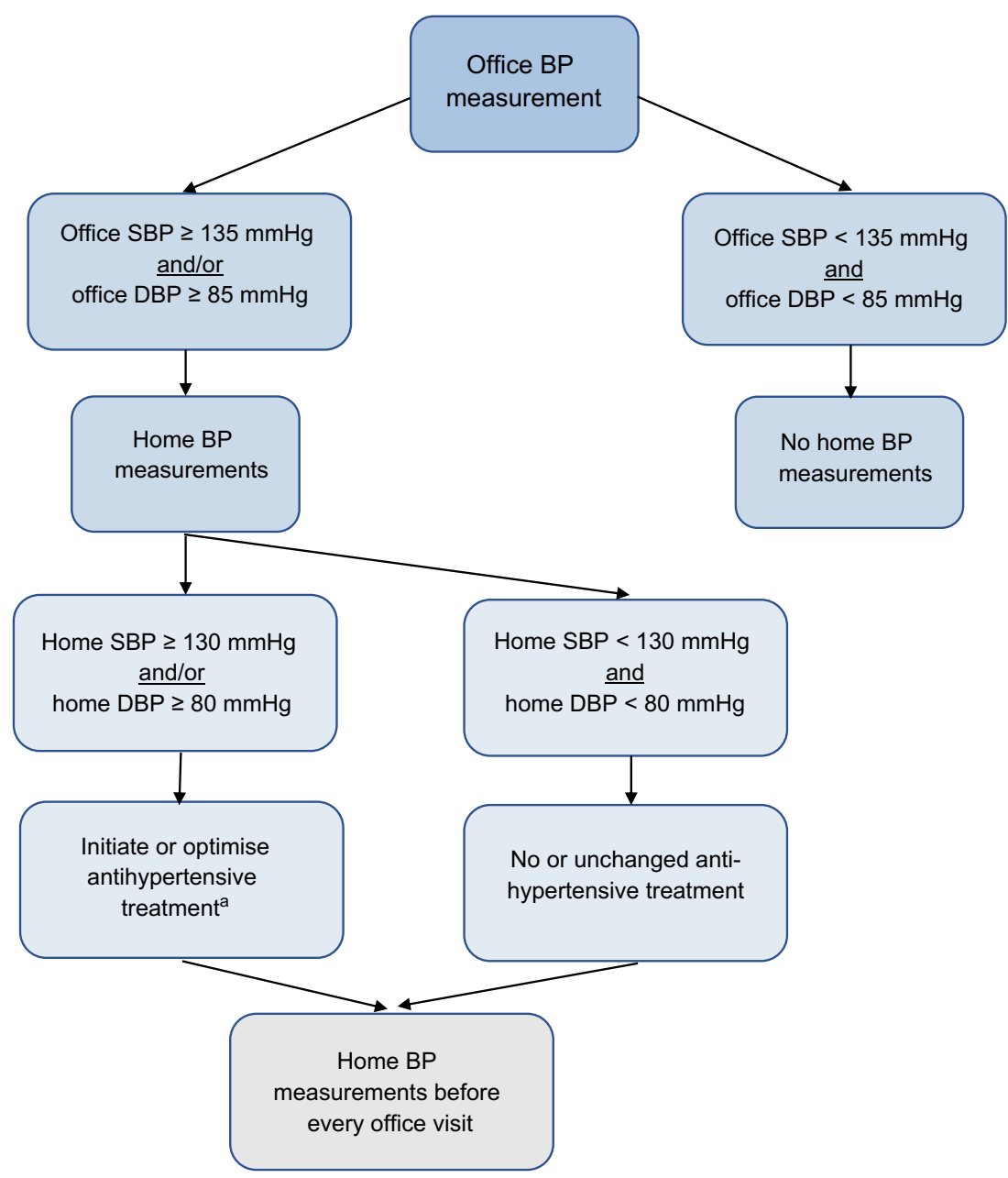

both office and home BP measurements were used for titrating the antihypertensive treatment to reach the dual therapeutic goals of home $\mathrm{BP}<130 \mathrm{mmHg}$ systolic and $<80 \mathrm{mmHg}$ diastolic, and ACR $<30 \mathrm{mg} / \mathrm{mmol}$ (Fig. 1). Antihypertensive treatment could also be initiated based on office BP measurements only, on the local obstetrician's decision, which was mainly the case during hospital admission in late pregnancy and during delivery.

Methyldopa was the primary antihypertensive agent used, with labetalol and slow-release nifedipine added when necessary.

\section{Categorising of women in early pregnancy based on BP In} accordance with our tight antihypertensive strategy with target for initiation of antihypertensive treatment at office BP $\geq 135$ / $85 \mathrm{mmHg}$ and home $\mathrm{BP} \geq 130 / 80 \mathrm{mmHg}$, the women were categorised into three groups (Fig. 2):

1. White coat hypertension. Defined as newly detected office $\mathrm{BP} \geq 135 \mathrm{mmHg}$ systolic and/or $\geq 85 \mathrm{mmHg}$ diastolic, and home $\mathrm{BP}<130 \mathrm{mmHg}$ systolic and $<80 \mathrm{mmHg}$ diastolic.
2. Chronic hypertension and/or kidney involvement. Chronic hypertension was defined as known prepregnancy hypertension, or newly detected office $\mathrm{BP} \geq 135 \mathrm{mmHg}$ systolic and/or $\geq 85 \mathrm{mmHg}$ diastolic with home $\mathrm{BP} \geq 130 \mathrm{mmHg}$ systolic and/or $\geq 80 \mathrm{mmHg}$ diastolic. Kidney involvement was defined as known or newly detected presence of diabetic nephropathy (ACR $\geq 30 \mathrm{mg} / \mathrm{mmol}$ ) or microalbuminuria (ACR 3-29 $\mathrm{mg} / \mathrm{mmol}$ ), based on two urine samples where possible. Women with known pre-pregnancy hypertension, where the antihypertensive treatment was withdrawn in early pregnancy $(n=2)$, and women with kidney involvement in early pregnancy without antihypertensive treatment $(n=3)$, were allocated to this group of women with hypertension.

3. Normotension. Defined as office $\mathrm{BP}<135 \mathrm{mmHg}$ systolic and $<85 \mathrm{mmHg}$ diastolic.

Definitions of hypertensive disorders Pregnancy-induced hypertensive disorders are defined as office $\mathrm{BP} \geq 140 \mathrm{mmHg}$ systolic and/or $\geq 90 \mathrm{mmHg}$ diastolic measured at least twice, 
Fig. 2 Categorisation of 222 women with pre-existing diabetes and home BP measurements in early pregnancy into groups: white coat hypertension, chronic hypertension and normotension

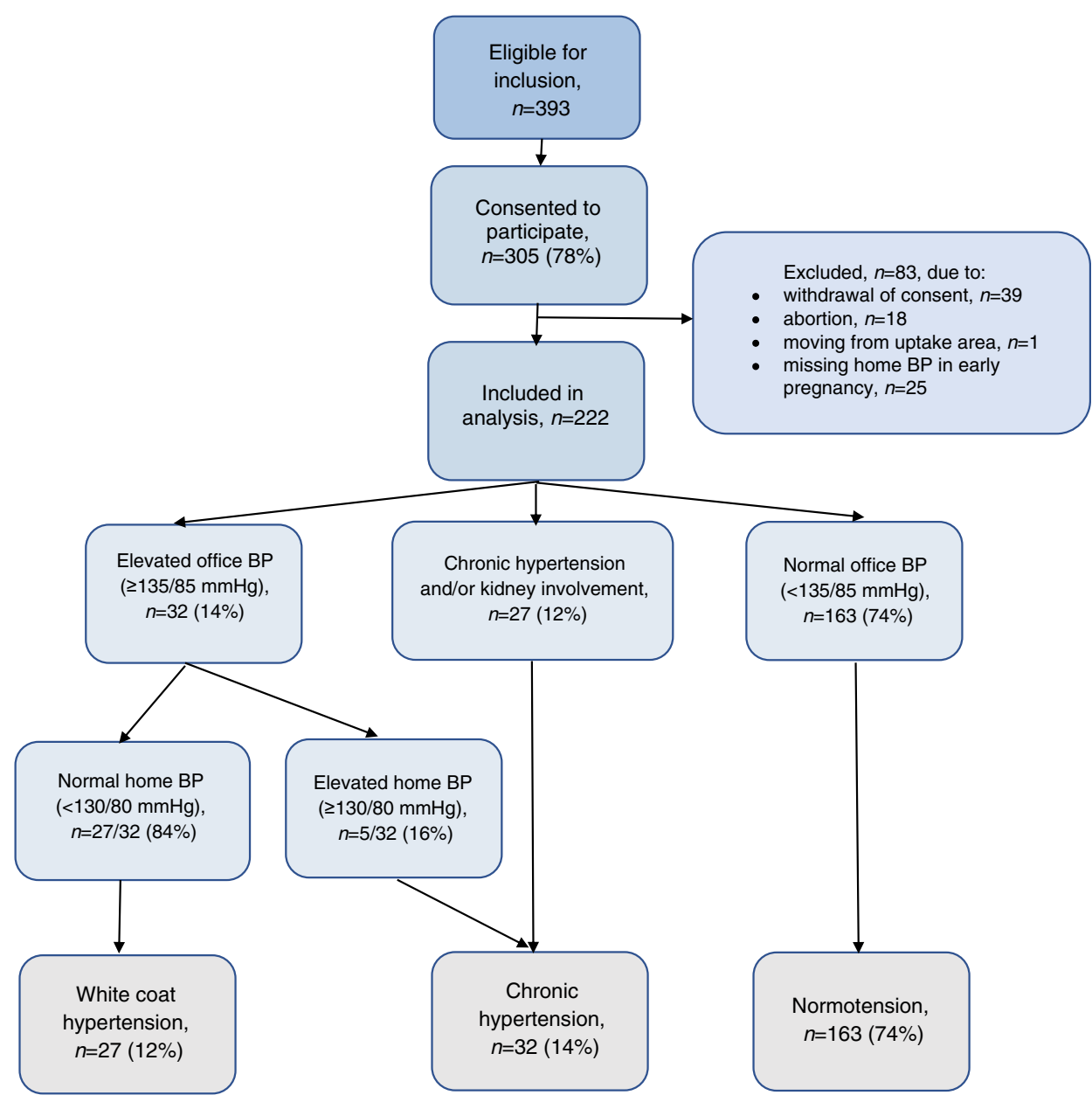

$4 \mathrm{~h}$ apart, after 20 weeks of gestation, and home $\mathrm{BP} \geq 130$ / $80 \mathrm{mmHg}$ when available, in agreement with international guidelines $[4,5]$. Pregnancy-induced hypertensive disorders include preeclampsia and gestational hypertension.

Preeclampsia is defined as hypertension developing after 20 weeks of gestation with the coexistence of either proteinuria $\geq+1$ on a sterile urine dipstick or symptoms from other organs defined as thrombocytopenia $\left(<100 \times 10^{9} / 1\right)$, renal insufficiency (serum creatinine concentrations $>100 \mu \mathrm{mol} / \mathrm{l}$ or a doubling of the serum creatinine concentration in the absence of other renal disease), impaired liver function (elevated blood concentrations of liver aminotransferases to twice normal concentration), pulmonary oedema, cerebral or visual symptoms [4]. In women with prior kidney involvement, superimposed preeclampsia was defined as an increase in either systolic or diastolic $\mathrm{BP}$ of $\geq 15 \%$ and office $\mathrm{BP} \geq 140 \mathrm{mmHg}$ systolic and/or $\geq 90 \mathrm{mmHg}$ diastolic on two occasions at least $4 \mathrm{~h}$ apart, with the coexistence of proteinuria $\geq+1$ on a sterile urine dipstick, regardless of changes in the degree of proteinuria.

Gestational hypertension is defined as pregnancy-induced hypertension without fulfilling the criteria for preeclampsia, regardless of onset of antihypertensive treatment. Where doubt existed about the diagnosis of preeclampsia or gestational hypertension, the cases were evaluated by the senior obstetrician (PD).

Diabetes and pregnancy care All women followed the pregnancy care programme for pregnant women with pre-existing diabetes at the two centres, mainly as previously described [1]. The women attended obstetric clinic appointments at approximately $8,12,20,27,33$ and 36 gestational weeks and every second week for diabetic clinic visits where office BP, glycaemic control and weight were registered, and a sterile urine dipstick was used to screen for proteinuria.

A low glycaemic index diet with a moderate amount of carbohydrates was recommended according to national guidelines on diabetes diet with focus on appropriate gestational weight gain according to pre-pregnancy BMI; BMI $<25 \mathrm{~kg} / \mathrm{m}^{2}: 10-15 \mathrm{~kg}$, BMI $25-29.9 \mathrm{~kg} / \mathrm{m}^{2}: 5-8 \mathrm{~kg}$ and $\mathrm{BMI} \geq 30 \mathrm{~kg} / \mathrm{m}^{2}: 0-5 \mathrm{~kg}$.

The women were advised to self-monitor plasma glucose before and $90 \mathrm{~min}$ after each main meal and at bedtime to obtain plasma glucose values of $4.0-6.0 \mathrm{mmol} / \mathrm{l}$ preprandially and $4.0-8.0 \mathrm{mmol} / 1$ postprandially. The targets for $\mathrm{HbA}_{1 \mathrm{c}}$ were $<50 \mathrm{mmol} / \mathrm{mol}(6.7 \%)$ before 20 weeks of gestation and $<40 \mathrm{mmol} / \mathrm{mol}(5.8 \%)$ after 20 weeks. In women with 
type 2 diabetes, oral hypoglycaemic agents including metformin and glucagon-like peptide-1 receptor analogues were discontinued at the first antenatal visit and insulin was initiated if indicated. In general, the women consulted a diabetes specialist approximately every 2 weeks throughout the pregnancy.

Prophylactic treatment with aspirin $75-150 \mathrm{mg} /$ day was recommended from 12 weeks to $36 / 37$ weeks of gestation to women with additional high risk of developing preeclampsia, i.e. with a history of preeclampsia in a previous pregnancy, kidney involvement or chronic hypertension. The variation in dose of aspirin was due to changes in treatment protocols during the study period.

Clinical data collection At first pregnancy visit, clinical variables were collected. $\mathrm{HbA}_{1 \mathrm{c}}$ was measured in capillary blood (DCA 2000; Bayer, Mishawaka, IN, USA). In women with $\geq+1$ for proteinuria, ACR was measured. Diabetic retinopathy was assessed by retinal photo screening [20]. Gestational age was assessed based on the first trimester nuchal translucency scan.

Pregnancy outcome Preterm delivery was defined as delivery before 37 completed weeks of gestation. Gestational weight gain was calculated as the last measured weight (mainly 12 weeks before delivery) minus self-reported pre-pregnancy weight [21]. Large for gestational age (LGA) and small for gestational age (SGA) infants were defined as birthweight $\geq 90$ th and $\leq 10$ th percentile adjusted for sex and gestational age, respectively [22]. Admission to the neonatal intensive care unit (NICU), perinatal mortality (between 22 weeks of gestation and 7 days of life), major congenital malformations (leading to death, causing a substantial future disability or requiring surgery), neonatal hypoglycaemia (defined as a plasma glucose value below $2.2 \mathrm{mmol} / \mathrm{l}$, measured within $4 \mathrm{~h}$ of life), jaundice (requiring phototherapy), transient tachypnoea (requiring continuous positive airway pressure for more than $60 \mathrm{~min}$ ) were noted. Perinatal morbidity was defined as the occurrence of at least one of the following complications: admittance to NICU, major congenital malformation, neonatal hypoglycaemia, jaundice or transient tachypnoea.

Statistical analysis Continuous data with normal distribution were reported as mean $( \pm \mathrm{SD})$, continuous data with skewed distribution as median (IQR) and categorical data as number $(\%)$.

Both women with white coat hypertension and women with chronic hypertension were compared with women with normotension. Continuous skewed data were transformed using logarithms. After transformation, all variables satisfied normality and Student's $t$ test was used for comparison of groups as well as for continuous normally distributed data. Categorical variables were compared by $\chi^{2}$ test or Fisher's exact test where appropriate. Data was available for more than $95 \%$ of the women unless otherwise stated.

Univariate logistic regression analysis was conducted in women without chronic hypertension in early pregnancy with pregnancy-induced hypertensive disorders (yes/no) as outcome variable. To identify possible independent risk factors for pregnancy-induced hypertensive disorders, multivariate logistic regression analysis was applied post hoc with pregnancy-induced hypertensive disorders as the dependent variable. Independent variables with $p<0.10$ in the univariate logistic regression analyses were included in the model; nulliparity (yes/no), pre-pregnancy BMI $\left(\mathrm{kg} / \mathrm{m}^{2}\right)$ and white coat hypertension (yes/no). BP values were not included in the analysis, as these values were used for categorising white coat hypertension.

\section{Ethics}

The protocol was in accordance with the Helsinki declaration and approved by the local ethical committee of the capital region of Denmark (H-15019186) and the local data agency (2012-58-0004, RH-2015-289, I-Suite: 04305). The study was registered at ClinicalTrials.gov (ID: NCT02890836). Written informed consent was obtained from all participants.

\section{Results}

In total, 32 out of 222 women with pre-existing diabetes were identified as having newly detected office $\mathrm{BP} \geq 135 / 85 \mathrm{mmHg}$ in early pregnancy. White coat hypertension was present in $84 \%$ (27/32) of these women, representing $12 \%$ (95\% CI 8\%, $17 \%$ ) of the total cohort. Chronic hypertension at baseline was found in 32 (14\%) women (chronic hypertension present before pregnancy $[n=19]$, kidney involvement $[n=8]$ and newly detected elevated BP both at the office and at home $[n=5]$ ) (Fig. 2). The remaining 163 women (74\%) were classified as normotensive. Baseline data are presented in Table 1.

Women with white coat hypertension were characterised by higher pre-pregnancy BMI $(p=0.011)$, higher home BP (systolic BP, $p<0.001 /$ diastolic BP, $p<0.001$ ) and higher prevalence of type 2 diabetes $(p=0.009)$ compared with normotensive women.

Pregnancy-induced hypertensive disorders developed more frequently in women with white coat hypertension in early pregnancy $(n=12,44 \%)$ compared with women with normotension $(n=36,22 \%)(p=0.013)$. The classic threshold for hypertension $(\geq 140 / 90 \mathrm{mmHg}$ ) was exceeded in most cases $(88 \%)$, at the onset of antihypertensive treatment. Both women with white coat hypertension and women with normotension in early pregnancy initiating antihypertensive treatment were mainly on monotherapy for median 21 and 
Table 1 Baseline data in 222 pregnant women with pre-existing diabetes categorised in early pregnancy according to presence of white coat hypertension, chronic hypertension or normotension

\begin{tabular}{|c|c|c|c|c|c|}
\hline Characteristic & $\begin{array}{l}\text { White coat } \\
\text { hypertension, } \\
n=27(12 \%)\end{array}$ & $\begin{array}{l}\text { Chronic } \\
\text { hypertension, } \\
n=32(14 \%)\end{array}$ & $\begin{array}{l}\text { Normotension, } \\
n=163(74 \%)\end{array}$ & $\begin{array}{l}p \text { value between } \\
\text { white coat hypertension } \\
\text { and normotension }\end{array}$ & $\begin{array}{l}p \text { value between } \\
\text { chronic hypertension } \\
\text { and normotension }\end{array}$ \\
\hline Type $1 /$ type 2 diabetes $^{\mathrm{a}}$ & $12(44) / 15(56)$ & $13(41) / 19(59)$ & $114(70) / 49(30)$ & 0.009 & 0.001 \\
\hline Duration of diabetes (years) & $6(2-16)$ & $8(3-22)$ & $11(3-18)$ & 0.234 & 0.911 \\
\hline Gestational age (days) & $80(63-91)$ & $67(60-93)$ & $71(59-88)$ & 0.148 & 0.234 \\
\hline Maternal age (years) & $33 \pm 7$ & $34 \pm 5$ & $32 \pm 5$ & 0.096 & 0.011 \\
\hline Pre-pregnancy weight $(\mathrm{kg})$ & $93(75-113)$ & $92(74-108)$ & $72(62-89)$ & 0.002 & $<0.001$ \\
\hline Pre-pregnancy BMI $\left(\mathrm{kg} / \mathrm{m}^{2}\right)$ & $31(25-40)$ & $34(26-37)$ & $26(23-31)$ & 0.011 & $<0.001$ \\
\hline $\mathrm{HbA}_{1 \mathrm{c}}(\mathrm{mmol} / \mathrm{mol})$ & $47 \pm 9$ & $51 \pm 12$ & $49 \pm 11$ & 0.409 & 0.495 \\
\hline $\mathrm{HbA}_{1 \mathrm{c}}(\%)$ & 7.7 & 8.2 & 7.9 & & \\
\hline Office systolic BP (mmHg) & $133 \pm 10$ & $130 \pm 13$ & $117 \pm 9$ & $<0.001$ & $<0.001$ \\
\hline Office diastolic BP (mmHg) & $87 \pm 5$ & $84 \pm 10$ & $74 \pm 6$ & $<0.001$ & $<0.001$ \\
\hline Home systolic BP (mmHg) & $117 \pm 7$ & $126 \pm 9$ & $109 \pm 8$ & $<0.001$ & $<0.001$ \\
\hline Home diastolic BP (mmHg) & $73 \pm 4$ & $77 \pm 7$ & $68 \pm 7$ & $<0.001$ & $<0.001$ \\
\hline Kidney involvement & - & $8(25)$ & - & - & - \\
\hline Microalbuminuria & - & $5(16)$ & - & - & - \\
\hline Diabetic nephropathy & - & $3(9)$ & - & - & - \\
\hline Diabetic retinopathy & $3 / 20(15)$ & $9 / 24(38)$ & $34 / 121(28)$ & 0.217 & 0.409 \\
\hline Nulliparous & $15(56)$ & $20(63)$ & $87(53)$ & 0.833 & 0.343 \\
\hline Nordic origin & $21(78)$ & $26(81)$ & $132(81)$ & 0.830 & 0.752 \\
\hline Smoking & $2(7)$ & $7(22)$ & $8(5)$ & 0.667 & 0.003 \\
\hline $\begin{array}{l}\text { Prophylactic aspirin initiated before } \\
16 \text { weeks of gestation }\end{array}$ & $5(19)$ & $25(78)$ & $25(15)$ & 0.775 & $<0.001$ \\
\hline $\begin{array}{l}\text { Previous preeclampsia (only parous } \\
\text { women) }\end{array}$ & $0 / 12(0)$ & $5 / 12(42)$ & $10 / 76(13)$ & 0.346 & 0.028 \\
\hline
\end{tabular}

Continuous data with normal distribution are reported as mean $\pm \mathrm{SD}$, data with skewed distribution as median (IQR) and categorical data as number (\%). Data were available for $\geq 95 \%$ of the women unless otherwise stated

${ }^{\text {a }}$ Prevalence of type 1 diabetes vs type 2 diabetes

12 days, respectively (Table 2). The overall prevalence of hypertensive disorders including chronic hypertension, gestational hypertension and preeclampsia was 36\% (80/222). Antihypertensive treatment was given in 64 of these 80 women. In 13 women hypertension developed very late in pregnancy or during delivery and, based on the local obstetrician's decision, antihypertensive treatment was not initiated. Three women in the group with chronic hypertension did not meet the criteria for antihypertensive treatment during pregnancy.

Univariate logistic regression analysis in women without chronic hypertension $(n=190)$ identified nulliparity, BMI and white coat hypertension as possible risk factors for pregnancyinduced hypertension (Table 3). The adjusted analysis suggested approximately double the risk of developing pregnancy-induced hypertensive disorders (OR 2.43 [CI $0.98,6.05]$ ) if white coat hypertension was present in early pregnancy, independently of pre-pregnancy BMI and parity $(p=0.056)$ (Table 3).

In total $27(12 \%)$ women developed preeclampsia. Twenty of these women developed preeclampsia before 37 completed weeks of pregnancy resulting in preterm delivery in 17 cases $(8 \%)$. Preeclampsia developed in four $(15 \%)$ women with white coat hypertension and in $14(9 \%)$ initially normotensive women (Table 2). All 27 women diagnosed with preeclampsia had $\mathrm{BP} \geq 140 / 90 \mathrm{mmHg}$ at two occasions at least $4 \mathrm{~h}$ apart accompanied by proteinuria. Five (19\%) women also had signs or symptoms from other organ systems, mainly impaired liver function.

Gestational age at delivery or preterm delivery were not associated with presence of white coat hypertension in early pregnancy (Table 2).

The mean birthweight $z$ score was lower in offspring of women with white coat hypertension compared with offspring of women with normotension $(p=0.006)$, with fewer infants born LGA $(p=0.029)$ (Table 2).

Use of prophylactic aspirin was not common among women with white coat hypertension but was mainly seen in the group not developing pregnancy-induced hypertensive disorders (Table $4, p=0.047$ ). All other early pregnancy clinical variables in women with white coat hypertension were similar 
Table 2 Pregnancy outcome in 222 pregnant women with pre-existing diabetes categorised in early pregnancy in three groups according to presence of white coat hypertension, chronic hypertension and normotension

\begin{tabular}{|c|c|c|c|c|c|}
\hline Outcome & $\begin{array}{l}\text { White coat } \\
\text { hypertension, } \\
n=27(12 \%)\end{array}$ & $\begin{array}{l}\text { Chronic } \\
\text { hypertension, } \\
n=32(14 \%)\end{array}$ & $\begin{array}{l}\text { Normotension, } \\
n=163(74 \%)\end{array}$ & $\begin{array}{l}p \text { value between } \\
\text { white coat hypertension } \\
\text { and normotension }\end{array}$ & $\begin{array}{l}p \text { value between } \\
\text { chronic hypertension } \\
\text { and normotension }\end{array}$ \\
\hline Pregnancy-induced hypertensive disorders & $12(44)$ & - & $36(22)$ & 0.013 & - \\
\hline Gestational hypertension & $8(30)$ & - & $22(13)$ & 0.045 & - \\
\hline Preeclampsia & $4(15)$ & $9(28)$ & $14(9)$ & 0.306 & 0.005 \\
\hline $\begin{array}{l}\text { Gestational age at diagnosis of } \\
\text { pregnancy-induced hypertension (days) }\end{array}$ & $247(238-255)$ & $238(220-247)^{\mathrm{a}}$ & $251(241-261)$ & 0.972 & 0.730 \\
\hline Systolic office BP at 36 weeks (mmHg) & $124 \pm 17$ & $128 \pm 14$ & $122 \pm 13$ & 0.447 & 0.028 \\
\hline Diastolic office BP at 36 weeks $(\mathrm{mmHg})$ & $82 \pm 9$ & $83 \pm 8$ & $79 \pm 8$ & 0.044 & 0.008 \\
\hline Systolic home BP at 36 weeks $(\mathrm{mmHg})^{\mathrm{b}}$ & $123 \pm 9$ & $126 \pm 11$ & $118 \pm 10$ & 0.073 & 0.003 \\
\hline Diastolic home BP at 36 weeks $(\mathrm{mmHg})^{\mathrm{b}}$ & $78 \pm 6$ & $77 \pm 7$ & $76 \pm 7$ & 0.326 & 0.577 \\
\hline $\mathrm{HbA}_{1 \mathrm{c}}$ at 36 weeks $(\mathrm{mmol} / \mathrm{mol})$ & $42 \pm 6$ & $40 \pm 5$ & $43 \pm 6$ & 0.327 & 0.010 \\
\hline $\mathrm{HbA}_{1 \mathrm{c}}$ at 36 weeks $(\%)$ & 7.0 & 6.5 & 7.1 & & \\
\hline $\begin{array}{l}\text { Office systolic BP at initiation of } \\
\text { antihypertensive treatment }(\mathrm{mmHg})\end{array}$ & $142 \pm 12$ & $142 \pm 18$ & $140 \pm 11$ & 0.570 & 0.631 \\
\hline $\begin{array}{l}\text { Office diastolic BP at initiation of } \\
\text { antihypertensive treatment }(\mathrm{mmHg})\end{array}$ & $90 \pm 4$ & $88 \pm 9$ & $92 \pm 6$ & 0.470 & 0.172 \\
\hline $\begin{array}{l}\text { Home systolic } \mathrm{BP} \text { at initiation of } \\
\text { antihypertensive treatment }(\mathrm{mmHg})^{\mathrm{c}}\end{array}$ & $140 \pm 10$ & $129 \pm 4$ & $136 \pm 13$ & 0.324 & 0.250 \\
\hline $\begin{array}{l}\text { Home diastolic BP at initiation of } \\
\text { antihypertensive treatment }(\mathrm{mmHg})^{\mathrm{c}}\end{array}$ & $89 \pm 8$ & $82 \pm 5$ & $88 \pm 5$ & 0.594 & 0.017 \\
\hline $\begin{array}{l}\text { Antihypertensive treatment given or initiated } \\
\text { during pregnancy }\end{array}$ & $10(37)$ & $29(91)$ & $25(15)$ & 0.007 & $<0.001$ \\
\hline Duration of antihypertensive treatment (days) & $21(6-41)$ & $237(149-262)$ & $12(7-33)$ & 0.460 & $<0.001$ \\
\hline Antihypertensive treatment with monotherapy & $8(80)$ & $13(46)$ & $20(77)$ & 0.842 & 0.022 \\
\hline Gestational age at delivery (days) & $262(260-272)$ & $261(253-268)$ & $263(257-268)$ & 0.710 & 0.024 \\
\hline Preterm delivery (<37 weeks) & $4(15)$ & $14(44)$ & $46(28)$ & 0.143 & 0.082 \\
\hline Gestational weight gain (g/week) & $346 \pm 205$ & $275 \pm 213$ & $372 \pm 167$ & 0.485 & 0.011 \\
\hline Birthweight (g) & $3180 \pm 682$ & $2919 \pm 717$ & $3439 \pm 574$ & 0.036 & $<0.001$ \\
\hline Birthweight $z$ score & $0.23 \pm 1.4$ & $0.02 \pm 1.1$ & $1.05 \pm 1.4$ & 0.006 & $<0.001$ \\
\hline SGA & $4(15)$ & $6(16)$ & $7(4)$ & 0.053 & 0.009 \\
\hline LGA & $5(19)$ & $5(16)$ & $66(40)$ & 0.029 & 0.008 \\
\hline Placental weight (g) & $631 \pm 158$ & $604 \pm 179$ & $718 \pm 167$ & 0.013 & 0.001 \\
\hline Admittance to NICU ${ }^{\mathrm{d}}$ & $6(26)$ & $10(33)$ & $36(27)$ & 0.954 & 0.461 \\
\hline Perinatal mortality ${ }^{\mathrm{e}}$ & $0(0)$ & $1(3)$ & $0(0)$ & 1.000 & 1.000 \\
\hline Perinatal morbidity ${ }^{\mathrm{e}}$ & $14(64)$ & $14(54)$ & $85(69)$ & 0.612 & 0.134 \\
\hline
\end{tabular}

Data are reported as mean $\pm \mathrm{SD}$, as median (IQR) or as number $(\%)$

Pregnancy-induced hypertensive disorders: development of gestational hypertension or preeclampsia

Gestational hypertension: hypertension (office BP $\geq 140 / 90 \mathrm{mmHg}$ at two consecutive occasions with at least $4 \mathrm{~h}$ between) after 20 weeks of gestation Preeclampsia: hypertension after 20 weeks of gestation with the coexistence of symptoms from other organs

Perinatal mortality: the delivery of a fetus showing no signs of life at 22 weeks of gestation or greater or death within 7 days of life

Perinatal morbidity: the occurrence of at least one of the following complications: major congenital malformation, neonatal hypoglycaemia, jaundice or transient tachypnoea

${ }^{\mathrm{a}}$ The gestational age is given for women with preeclampsia

${ }^{\mathrm{b}}$ Data were available in $71 \%(n=157)$ of the women

${ }^{\mathrm{c}}$ Data were available in 35 (78\%) (nine, seven and 19 women with white coat hypertension, chronic hypertension and normotension, respectively) of the 45 women who initiated antihypertensive treatment during pregnancy

${ }^{\mathrm{d}}$ Data were available in $80 \%(n=178)$ of the women

${ }^{\mathrm{e}}$ Data were available in $77 \%(n=171)$ women 
Table 3 Risk markers for the development of pregnancy-induced hypertensive disorders in 190 pregnant women with preexisting diabetes without chronic hypertension illustrated by univariate and multivariate logistic regression analysis

\begin{tabular}{lllr}
\hline Independent variable & OR & $95 \% \mathrm{CI}$ & $p$ value \\
\hline Univariate logistic regression analysis (unadjusted OR) & & & \\
Nordic origin (yes/no) & 1.5 & $0.60,3.61$ & 0.405 \\
Nulliparous (yes/no) & 3.0 & $1.47,6.17$ & 0.003 \\
White coat hypertension in early pregnancy (yes/no) & 2.8 & $1.21,6.57$ & 0.016 \\
Pre-pregnancy BMI $\left(\mathrm{kg} / \mathrm{m}^{2}\right.$ ) & 1.05 & $1.00,1.11$ & 0.040 \\
Aspirin initiated $<16$ weeks (yes/no) & 0.70 & $0.27,1.84$ & 0.471 \\
Type 1 diabetes (yes/no) & 0.80 & $0.40,1.58$ & 0.518 \\
Smoking at baseline & 0.762 & $0.156,3.734$ & 0.738 \\
Office systolic BP in early pregnancy (mmHg) & 1.07 & $1.04,1.12$ & $<0.001$ \\
Office diastolic BP in early pregnancy (mmHg) & 1.10 & $1.04,1.15$ & $<0.001$ \\
Home mean systolic BP in early pregnancy (mmHg) & 1.09 & $1.04,1.14$ & $<0.001$ \\
Home mean diastolic BP in early pregnancy (mmHg) & 1.08 & $1.03,1.14$ & 0.003 \\
Multivariate logistic regression analysis (adjusted OR) & & & \\
Nulliparous (yes/no) & 3.28 & $1.56,6.89$ & 0.002 \\
Pre-pregnancy BMI (kg/m ${ }^{2}$ ) & 1.05 & $1.00,1.11$ & 0.073 \\
White coat hypertension in early pregnancy (yes/no) & 2.43 & $0.98,6.05$ & 0.056 \\
\hline
\end{tabular}

regardless of whether they developed pregnancy-induced hypertensive disorders or not (Table 4).

\section{Discussion}

In this prospective cohort study in women with pre-existing diabetes, white coat hypertension in early pregnancy was seen in $84 \%$ of women with newly detected elevated office BP. Presence of white coat hypertension in early pregnancy was associated with a high risk of developing pregnancy-induced hypertensive disorders later in pregnancy.

The high prevalence of white coat hypertension among pregnant women with diabetes with newly identified elevated office BP is in accordance with the percentage described in pregnant women without diabetes $[7,8]$.

Table 4 Characteristics of 27 women with pre-existing diabetes and white coat hypertension in early pregnancy categorised according to development of pregnancy-induced hypertensive disorders or no pregnancy-induced hypertensive disorders

\begin{tabular}{|c|c|c|c|}
\hline Characteristic & $\begin{array}{l}\text { Development of pregnancy-induced } \\
\text { hypertensive disorders, } n=12(44 \%)\end{array}$ & $\begin{array}{l}\text { No development of pregnancy-induced } \\
\text { hypertensive disorders, } n=15(56 \%)\end{array}$ & $p$ value \\
\hline Type $1 /$ type 2 diabetes & $6(50) / 6(50)$ & $6(40) / 9(60)$ & 0.603 \\
\hline Gestational age at inclusion (days) & $75(60-87)$ & $85(67-112)$ & 0.435 \\
\hline Maternal age at inclusion (years) & $33 \pm 8$ & $34 \pm 6$ & 0.759 \\
\hline Duration of diabetes (years) & $6(1-14)$ & $6(2-20)$ & 0.899 \\
\hline Pre-pregnancy BMI (kg/m²) & $30(22-39)$ & $32(26-40)$ & 0.608 \\
\hline $\mathrm{HbA}_{1 \mathrm{c}}$ at inclusion $(\mathrm{mmol} / \mathrm{mol})$ & $44 \pm 9$ & $50 \pm 8$ & 0.124 \\
\hline $\mathrm{HbA}_{1 \mathrm{c}}$ at inclusion $(\%)$ & 7.3 & 8.1 & \\
\hline Office BP at inclusion (mmHg) & $135 \pm 12 / 88 \pm 5$ & $132 \pm 7 / 85 \pm 5$ & $0.568 / 0.138$ \\
\hline Systolic office BP $\geq 135 \mathrm{mmHg}$ & $4(33)$ & $8(53)$ & 0.299 \\
\hline Diastolic office $\mathrm{BP} \geq 85 \mathrm{mmHg}$ & $10(83)$ & $11(73)$ & 0.662 \\
\hline Home BP at inclusion (mmHg) & $117 \pm 5 / 75 \pm 5$ & $117 \pm 9 / 72 \pm 5$ & $0.924 / 0.084$ \\
\hline Diabetic retinopathy & $1(8)$ & $2(13)$ & 1.000 \\
\hline Nulliparous & $8(67)$ & $7(47)$ & 0.299 \\
\hline Smoking at inclusion & $0(0)$ & $2(13)$ & 0.489 \\
\hline Nordic origin & $8(67)$ & $13(87)$ & 0.357 \\
\hline Prophylactic aspirin & $0(0)$ & $5(33)$ & 0.047 \\
\hline
\end{tabular}

Continuous data with normal distribution are reported as mean $\pm \mathrm{SD}$, data with skewed distribution as median (IQR) and categorical data as number (\%) Pregnancy-induced hypertensive disorders: development of gestational hypertension or preeclampsia 
Our findings that almost half of the pregnant women with diabetes and white coat hypertension later progressed to hypertensive disorders is also in line with one observational study of 76 women without diabetes [7] describing that approximately half of the women with white coat hypertension in early pregnancy developed pregnancy-induced hypertensive disorders.

We followed the international guidelines using $140 / 90 \mathrm{mmHg}$ as the level for diagnosing hypertension $[4,5]$, but planned to initiate antihypertensive treatment at a slightly lower level. However, most of the women were diagnosed with hypertension at onset of antihypertensive treatment. Due to our tight antihypertensive goal, the threshold for white coat hypertension was at a slightly lower level in women with diabetes compared with women without diabetes. However, if the same criteria for white coat hypertension was used for women with diabetes as for those without diabetes $(\geq 140 / 90 \mathrm{mmHg}$ for office BP and $<135$ / $85 \mathrm{mmHg}$ for home BP), the percentage of women with elevated office BP having white coat hypertension was similar (91\% [10/ 11]). If the criteria were for office $B P$ to be elevated on two separate days, the percentage of white coat hypertension was still high $(82 \%$ [14/17]).

The current international recommendations to leave pregnant women with white coat hypertension untreated $[4,5]$ reduces the exposure of their fetuses to antihypertensive drugs. Whether or not pregnant women with white coat hypertension may benefit from antihypertensive treatment from early pregnancy remains speculative. We were unable to identify any clinically recorded variable in early pregnancy that could distinguish between women with white coat hypertension who developed pregnancy-induced hypertensive disorders and women who did not apart from a higher prevalence of prophylactic aspirin in women who did not develop pregnancy-induced hypertensive disorders, but numbers were small. Therefore, when white coat hypertension in early pregnancy is left untreated as current guidelines recommend, it is recommended that elevated office BP later in pregnancy is supplemented with home BP measurements to detect development of elevated home BP and a need for antihypertensive treatment. How newly detected white coat hypertension later in pregnancy should be managed needs to be explored in future studies. More widely used aspirin prophylaxis for pregnant women with diabetes than that seen in this study may be beneficial [23].

Based on our positive experience of treating pregnant women with diabetes with and without kidney involvement to the present tight office BP goal [13], this tight antihypertensive treatment strategy was chosen for the present study. The tight antihypertensive treatment strategy also included a target of home BP of $\leq 130 / 80 \mathrm{mmHg}$. It is reassuring that $130 / 80 \mathrm{mmHg}$ is close to the upper reference limit for home $\mathrm{BP}$ of $123 / 78 \mathrm{mmHg}$ in late pregnancy in healthy pregnant women of European origin without diabetes [17], and to the upper reference limits of Japanese women [16, 24, 25]. The overall incidence of hypertensive disorders in the current study was high (36\%) and in line with what has previously been reported $(40 \%)$ in pregnant women with pre-existing diabetes [2].

Univariate analysis identified white coat hypertension as a possible risk marker for developing pregnancy-induced hypertensive disorders. The adjusted analysis suggested approximately double the risk of developing pregnancy-induced hypertensive disorders if white coat hypertension was present in early pregnancy, indicating that white coat hypertension is a useful risk factor for development of pregnancy-induced hypertension. However, this was a post hoc analysis and the adjusted analysis yielded only a borderline significant result, therefore the findings need to be evaluated with a larger sample in other studies.

In women with white coat hypertension, the birthweight $z$ score was lower compared with the birthweight $z$ score of women with normotension, despite similar glycaemic control. Whether white coat hypertension per se or the increased rate of pregnancy-induced hypertensive disorders affect the birthweight due to some degree of vasculopathy remains speculative. Onset of antihypertensive treatment may play a role, but the median duration of hypertensive treatment was only a few weeks. Studies exploring the impact of antihypertensive treatment on fetal growth in women with pre-existing diabetes are warranted.

It is a strength of the study that a relatively large unselected cohort from a large geographical area is included. Chronic hypertension, diabetic nephropathy and microalbuminuria indicate an increased risk of pregnancy complications including preeclampsia and preterm delivery, so these cases were excluded before estimating the prevalence and pregnancy outcome in women with white coat hypertension. Further, all data were carefully validated, and all patient records were reviewed with focus on development of hypertensive disorders and antihypertensive treatment.

Prior to the study, a sample size estimation showed that approximately 400 women with pre-existing diabetes were needed to estimate the prevalence of white coat hypertension with a precision of $5 \%$. The study was not powered to detect differences in pregnancy outcome among women with and without white coat hypertension in early pregnancy, nevertheless, as it is presently the only study of its kind, we found it clinically meaningful to report pregnancy outcome, despite a small number of women with white coat hypertension and many variables tested, which makes the statistical evaluation less strong.

Further strengths of our study include using the device Microlife $\AA$ BP 3 A Plus, which is validated for use in pregnancy including if preeclampsia develops [18]. We used a comprehensive protocol for measuring home $\mathrm{BP}$ and all 18 measurements were available for most of the women in both early and late pregnancy. Home BP measurements were preferred to $24 \mathrm{~h} \mathrm{BP}$ measurements for convenience and cost of 
the repeated measurements needed. It is a limitation that not all initially included women reported home BP measurements and that not all women received antihypertensive treatment or prophylactic aspirin as indicated. It is possible that use of telemonitoring or smartphone applications might have led to increased compliance.

In conclusion, white coat hypertension is prevalent in women with pre-existing diabetes and may indicate a high risk of later development of pregnancy-induced hypertensive disorders. To distinguish between persistent white coat hypertension and onset of pregnancy-induced hypertension, repeated home BP monitoring is recommended when elevated office $\mathrm{BP}$ is detected.

Acknowledgements The authors are grateful to research-midwife M. A. Mikkelsen (Center for Pregnant Women with Diabetes, Rigshospitalet, Denmark) and A. Boa (Department of Obstetrics, Odense University Hospital, Denmark) for help with recruitment, collection and handling of data. Thanks to the nurses at the Center for Pregnant Women with Diabetes, Rigshospitalet, Denmark, for help with recruitment. We also thank the pregnant women for their time and interest in the study.

Data availability Source data are available on written request to MV.

Funding MV was funded by Rigshospitalet's Research Foundation. ERM was funded by Novo Nordisk Foundation (grant no. NNF14OC0009275).

Duality of interest The authors declare that there is no duality of interest associated with the manuscript.

Contribution statement The overall initiative for the study was taken by ERM, PD and MV. MV and BA collected the data. All co-authors contributed to the conception of the study, the analysis and interpretation of data. MV performed the statistical analysis and prepared the first draft of the manuscript. All co-authors revised the manuscript critically for important intellectual content. MV collected all comments from the co-authors and prepared the final draft. All co-authors approved the final version to be published. ERM is the guarantor of this work.

\section{References}

1. Norgaard SK, Vestgaard MJ, Jorgensen IL et al (2018) Diastolic blood pressure is a potentially modifiable risk factor for preeclampsia in women with pre-existing diabetes. Diabetes Res Clin Pract 138:229-237. https://doi.org/10.1016/j.diabres.2018.02.014

2. Cundy T, Slee F, Gamble G, Neale L (2002) Hypertensive disorders of pregnancy in women with type 1 and type 2 diabetes. Diabet Med 19(6):482-489. https://doi.org/10.1046/j.1464-5491.2002. 00729.x

3. Vestgaard M, Sommer MC, Ringholm L, Damm P, Mathiesen ER (2018) Prediction of preeclampsia in type 1 diabetes in early pregnancy by clinical predictors: a systematic review. J Matern Fetal Neonatal Med 31(14):1933-1939. https://doi.org/10.1080/ 14767058.2017.1331429

4. American College of Obstetricians and Gynecologists (2013) Hypertension in pregnancy. Report of the American College of Obstetricians and Gynecologists' Task Force on Hypertension in Pregnancy. Obstet Gynecol 122(5):1122-1131
5. Brown MA, Magee LA, Kenny LC et al (2018) Hypertensive disorders of pregnancy: ISSHP classification, diagnosis, and management recommendations for international practice. Hypertension 72(1):24-43. https://doi.org/10.1161/HYPERTENSIONAHA.117. 10803

6. Taylor J (2013) 2013 ESH/ESC guidelines for the management of arterial hypertension. Eur Heart J 34(28):2108-2109

7. Brown MA, Mangos G, Davis G, Homer C (2005) The natural history of white coat hypertension during pregnancy. BJOG 112(5):601-606. https://doi.org/10.1111/j.1471-0528.2004.00516. $\mathrm{x}$

8. Denolle T, Weber JL, Calvez C et al (2008) Diagnosis of white coat hypertension in pregnant women with teletransmitted home blood pressure. Hypertens Pregnancy 27(3):305-313. https://doi.org/10. 1080/10641950802000950

9. Magee LA, Singer J, von Dadelszen P, Group CS (2015) Less-tight versus tight control of hypertension in pregnancy. N Engl J Med 372(24):2367-2368

10. Sarafidis PA, Lazaridis AA, Ruiz-Hurtado G, Ruilope LM (2017) Blood pressure reduction in diabetes: lessons from ACCORD, SPRINT and EMPA-REG OUTCOME. Nat Rev Endocrinol 13(6):365-374. https://doi.org/10.1038/nrendo.2016.209

11. Ringholm L, Damm JA, Vestgaard M, Damm P, Mathiesen ER (2016) Diabetic nephropathy in women with preexisting diabetes: from pregnancy planning to breastfeeding. Curr Diab Rep 16(2):12. https://doi.org/10.1007/s11892-015-0705-3

12. Hommel E, Parving HH, Mathiesen E, Edsberg B, Damkjaer Nielsen M, Giese J (1986) Effect of captopril on kidney function in insulin-dependent diabetic patients with nephropathy. Br Med J (Clin Res Ed) 293(6545):467-470. https://doi.org/10.1136/bmj. 293.6545.467

13. Nielsen LR, Damm P, Mathiesen ER (2009) Improved pregnancy outcome in type 1 diabetic women with microalbuminuria or diabetic nephropathy: effect of intensified antihypertensive therapy? Diabetes Care 32(1):38-44. https://doi.org/10.2337/dc08-1526

14. Nielsen LH, Sundtoft I, Vestgaard M et al (2018) Præeclampsi og hypertension. Available from https://static1.squarespace.com/static/ $5467 \mathrm{abcce} 4 \mathrm{~b} 056 \mathrm{~d} 72594 \mathrm{db} 79 / \mathrm{t} / 5 \mathrm{bac} 84 \mathrm{e} 7652 \mathrm{dea} 0 \mathrm{a} 1 \mathrm{~b} 5 \mathrm{fb} 489 /$ 1538032877105/180924+PE-guideline-final+sandbjerg.pdf. Accessed 15 August 2019 [article in Danish]

15. Denolle T, Daniel JC, Calvez C, Ottavioli JN, Esnault V, Herpin D (2005) Home blood pressure during normal pregnancy. Am J Hypertens 18(9 Pt 1):1178-1180. https://doi.org/10.1016/j. amjhyper.2005.03.736

16. Ishikuro M, Obara T, Metoki $\mathrm{H}$ et al (2015) Parity as a factor affecting the white-coat effect in pregnant women: the BOSHI study. Hypertens Res 38(11):770-775. https://doi.org/10.1038/hr. 2015.97

17. Vestgaard M, Søholm JC, Nørgaard SK et al (2019) Home blood pressure in pregnancy - the upper reference limit. Blood Press Monit 24(4):191-198. https://doi.org/10.1097/MBP. 0000000000000386

18. Reinders A, Cuckson AC, Lee JT, Shennan AH (2005) An accurate automated blood pressure device for use in pregnancy and preeclampsia: the Microlife 3BTO-A. BJOG 112(7):915-920. https:// doi.org/10.1111/j.1471-0528.2005.00617.x

19. Bang LE, Christensen KL, Hansen KW, Skov K, Wiinberg N (2006) Diagnostisk blodtryksmåling - på døgnbasis, hjemme og $\mathrm{i}$ konsultationen. Available from http://www.dahs.dk/fileadmin/ BTmaaling_version-17.pdf. Accessed 15 August 2019 [article in Danish]

20. Vestgaard M, Ringholm L, Laugesen CS, Rasmussen KL, Damm P, Mathiesen ER (2010) Pregnancy-induced sight-threatening diabetic retinopathy in women with type 1 diabetes. Diabet Med 27(4):431435. https://doi.org/10.1111/j.1464-5491.2010.02958.x 
21. Jensen DM, Damm P, Sorensen B et al (2003) Pregnancy outcome and prepregnancy body mass index in 2459 glucose-tolerant Danish women. Am J Obstet Gynecol 189(1):239-244. https://doi.org/10. 1067/mob.2003.441

22. Marsal K, Persson PH, Larsen T, Lilja H, Selbing A, Sultan B (1996) Intrauterine growth curves based on ultrasonically estimated foetal weights. Acta Paediatr 85(7):843-848. https://doi.org/10. 1111/j.1651-2227.1996.tb14164.x

23. Rolnik DL, Wright D, Poon LC et al (2017) Aspirin versus placebo in pregnancies at high risk for preterm preeclampsia. N Engl J Med 377(7):613-622. https://doi.org/10.1056/NEJMoa1704559

24. Mikami Y, Takai Y, Era S et al (2017) Provisional criteria for the diagnosis of hypertension in pregnancy using home blood pressure measurements. Hypertens Res 40(7):679-684. https://doi.org/10. 1038/hr.2017.6

25. Iwama $\mathrm{N}$, Metoki $\mathrm{H}$, Ohkubo $\mathrm{T}$ et al (2016) Maternal clinic and home blood pressure measurements during pregnancy and infant birth weight: the BOSHI study. Hypertens Res 39(3):151-157. https://oi.org/10.1038/hr.2015.108

Publisher's note Springer Nature remains neutral with regard to jurisdictional claims in published maps and institutional affiliations. 